\title{
Radiographic Determination of Hip Rotation Center and Femoral Offset in Japanese Adults: A Preliminary Investigation toward the Preoperative Implications in Total Hip Arthroplasty
}

\author{
Taichiro Takamatsu, ${ }^{1}$ Takaaki Shishido, ${ }^{1}$ Yasuhito Takahashi, ${ }^{1,2}$ Toshinori Masaoka, \\ Toshiyuki Tateiwa, ${ }^{1}$ Kosuke Kubo, ${ }^{1}$ Kenji Endo, ${ }^{1}$ Masaya Aoki, ${ }^{1}$ and Kengo Yamamoto ${ }^{1}$ \\ ${ }^{1}$ Department of Orthopaedic Surgery, Tokyo Medical University, 6-7-1 Nishishinjuku, Shinjuku-ku, Tokyo 160-0023, Japan \\ ${ }^{2}$ Department of Bone and Joint Biomaterial Research, Tokyo Medical University, 6-7-1 Nishishinjuku, Shinjuku-ku, \\ Tokyo 160-0023, Japan \\ Correspondence should be addressed to Takaaki Shishido; tstmu@tokyo-med.ac.jp
}

Received 28 May 2015; Revised 29 September 2015; Accepted 7 October 2015

Academic Editor: Konstantinos Anagnostakos

Copyright ( 2015 Taichiro Takamatsu et al. This is an open access article distributed under the Creative Commons Attribution License, which permits unrestricted use, distribution, and reproduction in any medium, provided the original work is properly cited.

\begin{abstract}
The values of hip rotation center (HRC) and femoral offset (FO) evaluated according to Caucasian anatomical landmarks have been regarded as a useful reference also for Japanese patients in total hip arthroplasty (THA). In a strict sense, however, since there can be racial differences among their anatomical morphologies, it is clinically important to reconsider those parameters for the Japanese. In the present study, in order to investigate correlations among hip and pelvic morphometric parameters, frontal radiographs were taken from 98 Japanese adults (60 males and 38 females) without acetabular dysplasia and arthropathy in the standing position. Their mean age was $62.0 \pm 16.7$ years. The horizontal position of HRC was significantly correlated with the pelvic width in both genders $(P=0.0026$ and 0.0010 for the males and the females, resp.). The vertical position of HRC was significantly correlated with the teardrop-sacroiliac distance in the males $(P=0.0003)$ and with the pelvic cavity height in the females $(P=0.0067)$. However, in both genders, there were no correlations among FO and the other parameters analyzed in this study. Our present findings might contribute to theoretical implications of an appropriate HRC position for Japanese OA patients in THA.
\end{abstract}

\section{Introduction}

Osteoarthritis (OA) of hip can be divided into primary and secondary forms [1-5]. The primary OA is generally regarded to be associated with underlying abnormalities of articular cartilage without an anatomical abnormality or specific disease process, which is more common in Caucasians than in non-Caucasians $[2,3]$. On the other hand, the primary OA is a quite rare condition in Japan, and its prevalence was reported by only $0.65 \sim 9 \%$ among Japanese patients with hip OA [35]. Since the secondary OA involves congenital or developmental anatomic abnormalities such as acetabular dysplasia, it is particularly difficult to identify an original anatomical position for patients in total hip arthroplasty (THA). The hip rotation center (HRC) and femoral offset (FO) are important factors affecting clinical outcomes for THA, the optimization of which can lead to maximizing an implant durability and mechanical function in a replaced hip joint. In general, high positioning of an acetabular component can induce the reduced muscle strength and the increased prosthetic wear after THA, ultimately leading to the revision surgery [6-11]. When patients with the small FO stand on one leg, large strength of abductor muscle is required, and this condition increases stresses in hip prosthetic surfaces. In addition, these patients may frequently undergo the femoropelvic impingement and subsequent dislocation $[12,13]$.

Despite such importance for considering the anatomical parameters regarding HRC and FO, there is difficulty in precisely determining their optimal positions especially in patients who have a bilateral OA with substantial destruction of both hips (namely, due to no clear landmark available in the unaffected side of the hips). Thus, it is of great importance 
to rationalize the averaged target values of $\mathrm{HRC}$ and FO. Several regression formulae to assess HRC from pelvic morphologies have been reported previously for Caucasians [14-17]. Nevertheless, it should be noted that hip and pelvic morphologies can significantly differ by races [18-21]. In this context, it is questionable whether those formulae are directly applicable for non-Caucasians or not. To date, there have been few studies on rationalizing HRC and FO values for Japanese OA patients. In this study, we evaluated HRC and $\mathrm{FO}$ by using the plain frontal radiographs of the hips (including the pelvises) for the ultimate goal of determining their appropriate values for Japanese adults.

\section{Methods}

2.1. Subjects and the Studied Morphometric Parameters. This study was preliminary approved by the Institutional Review Board (IRB) of Tokyo Medical University, and a written informed consent was provided before undergoing any studyrelated procedures. We performed prospective study in a total of 98 Japanese adults (60 males and 38 females) hospitalized continuously at our institution for an orthopaedic disorder elsewhere except OA. Note that we did not include the patients who had arthropathy as well as acetabular dysplasia with a sharp angle of $>45^{\circ}$ and CE angle of $<20^{\circ}$. In addition, the patients with joint space narrowing and spur formation were not included in this analysis. The mean age of those patients was 62 years (ranging from 16 to 90 years), and we obtained frontal radiographs of the hips (including the pelvises) for the assessment of HRC and FO in the standing position as previously performed in the similar studies [14$16,22]$. The morphological evaluations using the radiographs were made in both hips of each patient, and then the obtained values were averaged.

The evaluated hip morphometric parameters of $\mathrm{H} 1-\mathrm{H} 3$ were shown in Figure 1, the definitions of which were given as follows:

H1: horizontal distance (HD, length in perpendicular line between HRC and vertical line across inferior edge of teardrop center).

H2: vertical distance (VD, length in perpendicular line between HRC and tangential line to inferior edge of teardrop center).

H3: femoral offset (FO, length in perpendicular line between HRC and femoral axis).

In addition, we evaluated the pelvic morphometric parameters of $P 1-P 7$ shown in Figure 2, the definitions of which were given as follows:

P1: pelvic width (PW).

P2: pelvic cavity width (PCW).

P3: interteardrop distance (ITD).

P4: pelvic height (PH).

P5: teardrop edge-sacroiliac distance (TSD).

P6: pelvic cavity height ( $\mathrm{PCH})$.

P7: ilium height from teardrop edge (IHT).

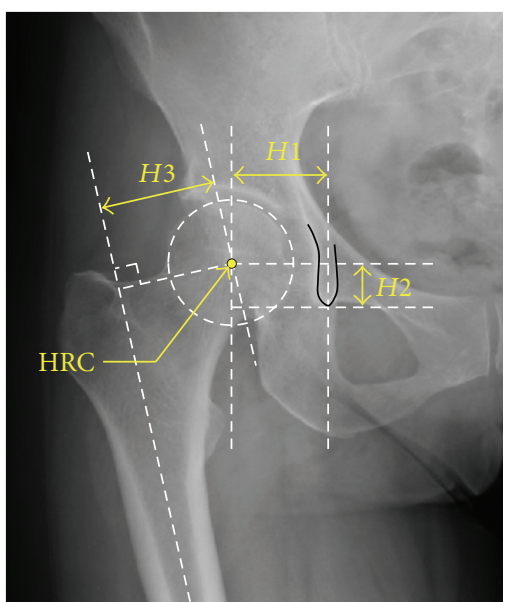

$H 1$ : horizontal distance (HD)

H2: vertical distance (VD)

H3: femoral offset (FO)

FIGURE 1: Hip morphometric parameters $(H 1-H 3)$ analyzed in this study (cf. Section 2.1).

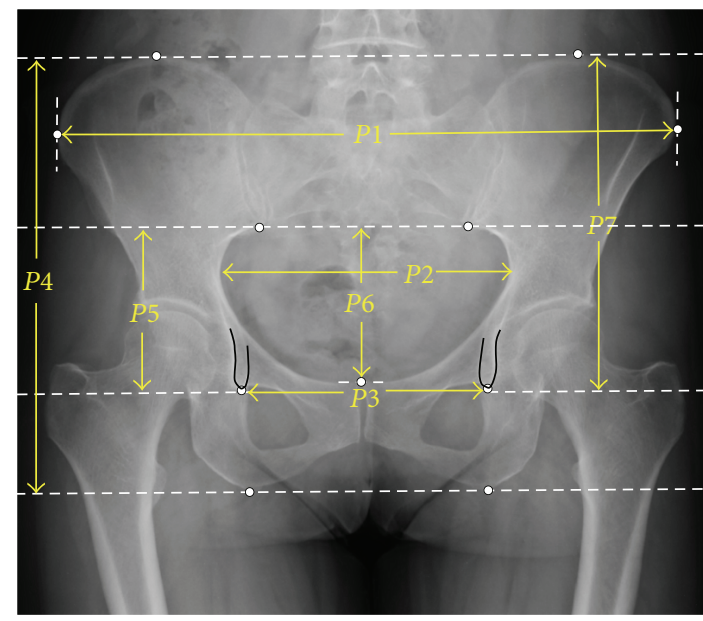

P1: pelvic width $(\mathrm{PW})$

$P$ 2: pelvic cavity width (PCW)

$P 3$ : inter-teardrop distance (ITD)

P4: pelvic height $(\mathrm{PH})$

P5: teardrop edge-sacroiliac distance (TSD)

P6: pelvic cavity height $(\mathrm{PCH})$

P7: ilium height from teardrop edge (IHT)

FigURE 2: Pelvic morphometric parameters $(P 1-P 7)$ analyzed in this study (cf. Section 2.1).

All these parameters were assessed by several observers (at least three orthopaedic surgeons among the authors of this study). The measured values were averaged and were eventually recorded as the analyzed parameters of $H 1-H 3$ and $P 1-P 7$.

2.2. Statistical Analysis. Quantitative variables were described by the mean \pm SD. Pearson's correlation coefficients $(r)$ were calculated and used to evaluate bivariate linear relations among the studied parameters. The variability of 


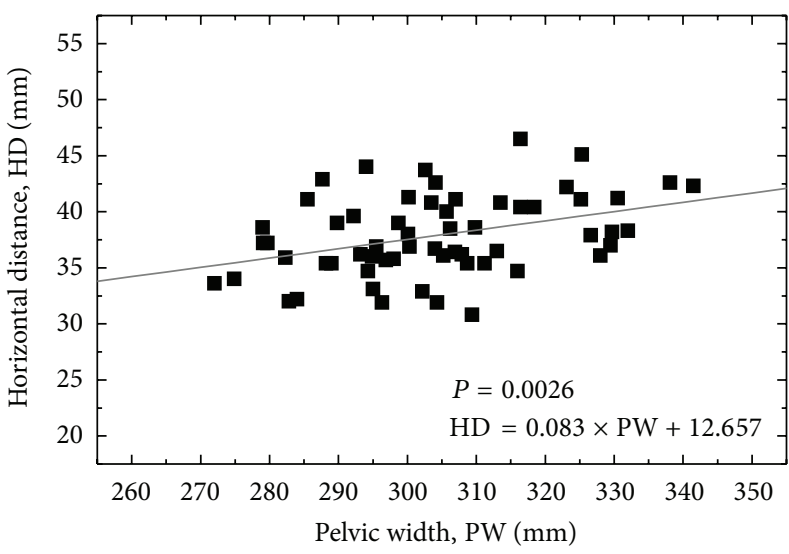

(a) Males

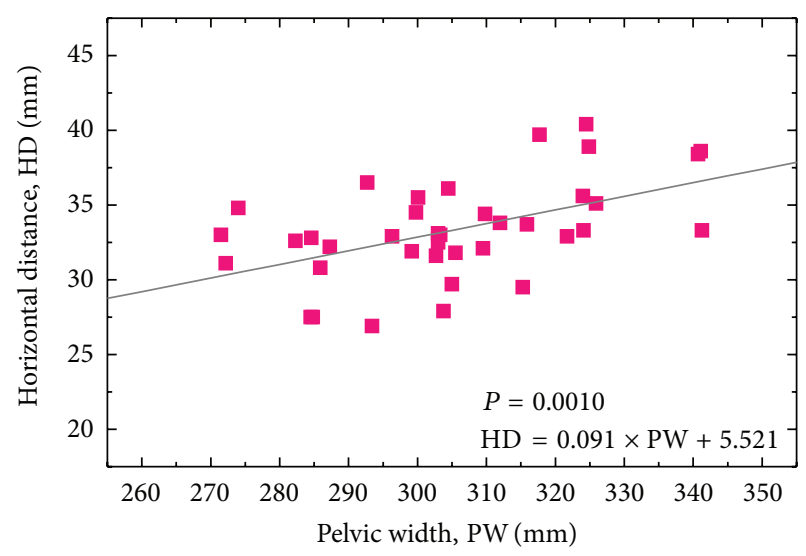

(b) Females

FIGURE 3: Correlation between pelvic width (PW) and horizontal distance (HD, length in perpendicular line between HRC and vertical line across inferior edge of teardrop center) in the Japanese males (a) and females (b). A linear line of fit is given in each diagram ( $r=0.381$, $n=60, P=0.0026$, and $\mathrm{HD}=0.083 \times \mathrm{PW}+12.657$, for the males; $r=0.51, n=38, P=0.0010$, and $\mathrm{HD}=0.091 \times \mathrm{PW}+5.521$, for the females).

TABLE 1: Mean values and standard deviation (mean $\pm \mathrm{SD}, \mathrm{mm}$ ) of hip morphometric parameters analyzed in the Japanese males and females.

\begin{tabular}{lccc}
\hline & Males & Females & Total \\
\hline Horizontal distance, HD (mm) & $37.8 \pm 3.5$ & $33.3 \pm 3.2$ & $36.2 \pm 4.0$ \\
Vertical distance, VD (mm) & $15.8 \pm 3.0$ & $15.7 \pm 4.2$ & $15.2 \pm 3.8$ \\
Femoral offset, FO (mm) & $36.0 \pm 5.8$ & $33.4 \pm 4.9$ & $34.3 \pm 5.8$ \\
\hline
\end{tabular}

sensitivity and specificity estimates was indicated by $95 \%$ exact confidence intervals. A software package SPSS version 20.0 (SPSS Inc., Chicago, IL, USA) was used for the statistical analysis. A $P<0.05$ was considered statistically significant.

\section{Results}

The mean values of $\mathrm{HD}, \mathrm{VD}$, and FO for the Japanese males were obtained as $37.8 \pm 3.5,15.8 \pm 3.0$, and $36.0 \pm 5.8 \mathrm{~mm}$, while those for the females were $33.3 \pm 3.2,15.7 \pm 4.2$, and $33.4 \pm 4.9 \mathrm{~mm}$, respectively (Table 1). Figures 3(a)-3(b) show the relationship between $\mathrm{HD}$ and $\mathrm{PW}$ in the males and females, respectively. As depicted in Figure 3, significant positive correlations were noted between HD and PW values in both genders $(r=0.381$ and $P=0.0026$ for the males, and $r=0.51$ and $P=0.0010$ for the females). The solid lines are a liner regression fit which indicates the relationship as follows: $\mathrm{HD}=0.083 \times \mathrm{PW}+12.657$ (for the males) and $\mathrm{HD}=$ $0.091 \times \mathrm{PW}+5.521$ (for the females). In the Japanese males, a significant positive correlation was also observed between VD and TSD values $(r=0.45, P=0.0003$, and $\mathrm{VD}=0.179 \times$ TSD + 3.036) (Figure 4). On the other hand, in the Japanese females, a significant positive correlation was found between $\mathrm{VD}$ and PCH values $(r=0.43, P=0.0067$, and $\mathrm{VD}=0.098$ $\times \mathrm{PCH}+9.692)($ Figure 5). However, in both genders, FO parameter was not correlated with any other morphological parameters analyzed in this study.

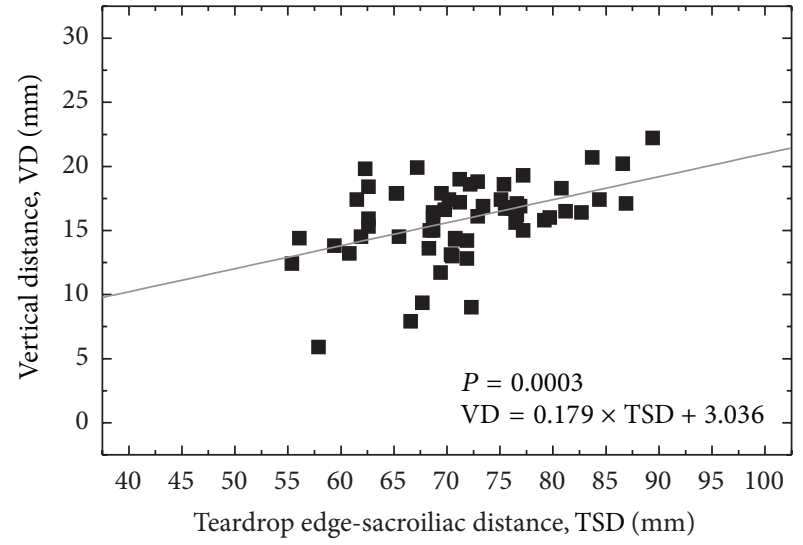

Figure 4: Correlation between teardrop edge-sacroiliac distance (TSD) and vertical distance (VD, length in perpendicular line between HRC and tangential line to inferior edge of teardrop center) in the Japanese males. A linear line of fit is given in the diagram $(r=0.45, n=60, P=0.0003$, and $\mathrm{VD}=0.179 \times \mathrm{TSD}+3.036)$.

\section{Discussion}

The geometrical effects of HRC and FO on a clinical outcome of THA have been previously discussed by several authors [6-17]. The mathematical considerations made by Johnston et al. [6] suggested that the improved mechanical function can be accomplished by placing HRC medially, inferiorly, and anteriorly. In other words, HRC reconstructed at high and lateral position can increase resultant forces and moments generated in prosthesis, possibly inducing a formation of wear debris and subsequent implant loosening [6-11]. On the other hand, it was reported that a lowering of FO reduces an abductor muscle force, moment arm, and range of motion, which can impose an increased risk of impingement between greater trochanter and acetabulum wall [14-17]. Nevertheless, an excessive FO can result in the increased stresses to 


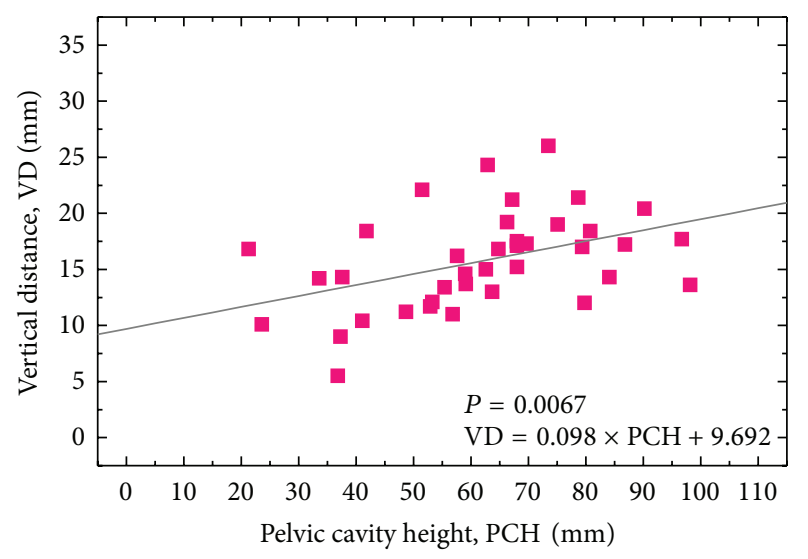

FIGURE 5: Correlation between pelvic cavity height (PCH) and vertical distance (VD, length in perpendicular line between HRC and tangential line to inferior edge of teardrop center) in the Japanese females. A linear line of fit is given in the diagram $(r=0.43$, $n=38, P=0.0067$, and VD $=0.098 \times \mathrm{PCH}+9.692)$.

femoral neck and also in pain at greater trochanter area [23].

Although, in principle, the position of HRC in OA patients should be reconstructed at the original position of their acetabula at the time of THA, there were indeed no rigorous anatomical landmarks for Japanese patients. The unaffected contralateral hip can provide a good anatomical indication for HRC for individual patient, but, as mentioned in the Introduction section, it is quite difficult to determine an appropriate HRC value especially in the case of patient affecting the bilateral hip OA.

To date, various methodologies and regression formulae for determining HRC have been reported via radiographic analyses. Ranawat et al. [14] suggested constructing an isosceles triangle with side lengths of $0.2 \times \mathrm{PH}$ from the point located at $5 \mathrm{~mm}$ lateral to the intersection of Koeler's and Shenton's lines. Pierchon et al. [15] reported that $\mathrm{HD}=0.2$ $\times$ ITD in males and HD $=0.18 \times$ ITD in females, and HD $=0.3 \times \mathrm{PCH}$ in males and $\mathrm{HD}=0.25 \times \mathrm{PCH}$ in females. Fessy et al. [16] reported that $\mathrm{VD}=0.204 \times \mathrm{TSD}-0.794$ in both genders. John and Fisher [17] suggest placing HRC at the position of $0.13 \times \mathrm{PH}$ lateral and $0.07 \times \mathrm{PH}$ superior to the teardrop in both genders. In addition, Schofer et al. [22] compared the methodological validations among them and concluded that the calculation according to Fessy et al. [16] provided the most precise and reliable determination of HRC (i.e., VD $=0.204 \times$ TSD -0.794 ). On the other hand, in the present study analyzed in Japanese population, the regression formulae were obtained as $\mathrm{HD}=0.083 \times \mathrm{PW}+12.657$ and $\mathrm{VD}$ $=0.179 \times \mathrm{TSD}+3.036$ (for the males) and $\mathrm{HD}=0.091 \times \mathrm{PW}$ +5.521 and $\mathrm{VD}=0.098 \times \mathrm{PCH}+9.692$ (for the females). The only similarity between Fessy's equation and the present ones can be found in the positive correlations between VD and TSD in the males (cf. Figure 4), but the slope of the regression formula is much lower in our study than Fessy's formula (0.098 versus 0.204$)$. In the Japanese females, VD did not significantly correlate TSD, but PCH. The above differences in the regression formulae can be interpreted due to racial and gender variations in their hip and pelvic morphologies [18-21]. Lavy et al. [21] reported that Japanese hips were more dysplastic than British hips and that, within the same racial group, women were more dysplastic than men. Such differences in the intrinsic hip morphology, thus, could lead to the variations of $\mathrm{HD}, \mathrm{VD}$, and $\mathrm{FO}$ values depending on races as well as genders.

A pioneering study on HRC analyzed in Japanese population was conducted by Fujii et al. [24], which showed that the males had the hip parameters of $\mathrm{HD}=39.0 \pm 3.0$ and $\mathrm{VD}=$ $15.0 \pm 3.2 \mathrm{~mm}$ and the females had those of $\mathrm{HD}=34.1 \pm 2.7$ and $15.4 \pm 2.9 \mathrm{~mm}$. These values show excellent agreement with those obtained in the present study (i.e., $\mathrm{HD}=37.8 \pm 3.5$ and $\mathrm{VD}=15.8 \pm 3.0$ for men; $\mathrm{HD}=33.3 \pm 3.2$ and $\mathrm{VD}=$ $15.7 \pm 4.2$ for women). On the other hand, we obtained the mean FO value as $36.0 \pm 5.8$ and $33.4 \pm 4.9 \mathrm{~mm}$ for the Japanese men and women, respectively, and a similar FO value was previously reported as $37.1 \pm 4.6 \mathrm{~mm}$ in Japanese population [25]. However, the mean FO values in Western populations were markedly different from those in the Japanese, which were reported as $43.0 \pm 6.8$ [26], 42.6 (ranging from 26.9 to 53.9) [27], and $42.2 \pm 5.1 \mathrm{~mm}$ [28]. The current results obtained from the Japanese showed that the FO value was not significantly correlated with any pelvic morphometric parameters.

Finally, we mention that this study had the following limitations. The unmatched numbers in the subjects between men and women were examined ( $n=60$ for men, and $n=38$ for women) and the study involved their broad age ranges $(62.0 \pm 16.7$ years). In addition, since the conventional plane radiographs correspond to the projection on the frontal view in a 2-dimensional (2D) plane, the FO measurement might lead to providing relatively larger errors or variations depending on rotation conditions of the femurs (cf. femoral anteversion and external rotation) as compared to the other studied parameters. Sariali et al. [28] found that the 3-dimensional (3D) morphological data analyzed by using computed tomography (CT) scanning provided $3.5 \mathrm{~mm}$ larger FO in white patients undergoing THA, as compared to $2 \mathrm{D}$ measurement of its projection on the frontal plane. Therefore, 3D CT analysis would be more preferable to find anatomical correlations regarding FO, but it must rely on the future study. Despite the above limitations, the present radiographic analyses showed positive correlations between HRC and pelvic morphometric parameters in Japanese adults (HD versus PW and VD versus TSD, for the males; HD versus PW and VD versus PCH for the females), which might be conducive to appropriately defining the proper hip anatomic landmarks.

By most experienced hip surgeons, it can be (theoretically) agreed that the optimum locations for HRC and FO of THA are the original anatomical positions, but, from the practical viewpoints of hip reconstructions, the theoretical placement of prostheses would not be always applicable due to the presence of large acetabular defects. In such difficult cases, the reconstructions can be performed by standardsized cemented cups with bone impaction grafting $[29,30]$, custom-made prostheses [31], oversized prostheses [32, 33], 
and high HRC (typically, in the order of several millimeters superior to the anatomical center) $[8,34]$. Russotti and Harris [8] explained that high HRC in THA was not a crucial parameter for long-term fixation of cemented acetabular components. In addition, they recommended placing an acetabular cup at a more superior but not more lateral position of HRC in a difficult acetabular reconstruction [8]. In addition, it was also reported that superior cup position was not associated with concomitant lateralization $[8,34]$. However, it was confirmed that high HRC can result in significantly higher aseptic loosening rates in femur rather than acetabulum $[7,34]$ as well as the increased risk of dislocation from impingement [34]. In the above contexts, it has not been fully clarified yet how much nonanatomical positioning of HRC can be allowed in terms of the long-term stability in the fixation. Therefore, it is of great importance to more rigorously define the "safe zone" of HRC and FO for THA, and we believe that the present results will contribute to promoting such studies in the future.

\section{Conflict of Interests}

All authors declare that there is no conflict of interests regarding the publication of this paper.

\section{References}

[1] R. Ganz, M. Leunig, K. Leunig-Ganz, and W. H. Harris, “The etiology of osteoarthritis of the hip: an integrated mechanical concept," Clinical Orthopaedics and Related Research, vol. 466, no. 2, pp. 264-272, 2008.

[2] F. T. Hoaglund and L. S. Steinbach, "Primary osteoarthritis of the hip: etiology and epidemiology," The Journal of the American Academy of Orthopaedic Surgeons, vol. 9, no. 5, pp. 320-327, 2001.

[3] S. Dagenais, S. Garbedian, and E. K. Wai, "Systematic review of the prevalence of radiographic primary hip osteoarthritis," Clinical Orthopaedics and Related Research, vol. 467, no. 3, pp. 623-637, 2009.

[4] S. Nakamura, S. Ninomiya, and T. Nakamura, "Primary osteoarthritis of the hip joint in Japan," Clinical Orthopaedics and Related Research, no. 241, pp. 190-196, 1989.

[5] S. Jingushi, S. Ohfuji, M. Sofue et al., "Multiinstitutional epidemiological study regarding osteoarthritis of the hip in Japan," Journal of Orthopaedic Science, vol. 15, no. 5, pp. 626-631, 2010.

[6] R. C. Johnston, R. A. Brand, and R. D. Crowninshield, "Reconstruction of the hip. A mathematical approach to determine optimum geometric relationships," Journal of Bone and Joint Surgery Series: A, vol. 61, no. 5, pp. 639-652, 1979.

[7] S. A. Yoder, R. A. Brand, D. R. Pedersen, and T. W. O'Gorman, "Total hip acetabular component position affects component loosening rates," Clinical Orthopaedics and Related Research, vol. 228, pp. 79-87, 1988.

[8] G. M. Russotti and W. H. Harris, "Proximal placement of the acetabular component in total hip arthroplasty. A longterm follow-up study," The Journal of Bone \& Joint SurgeryAmerican Volume, vol. 73, no. 4, pp. 587-592, 1991.

[9] B. J. McGrory, B. F. Morrey, T. D. Cahalan, K.-N. An, and M. E. Cabanela, "Effect of femoral offset on range of motion and abductor muscle strength after total hip arthroplasty," The
Journal of Bone and Joint Surgery - British Volume, vol. 77, no. 6, pp. 865-869, 1995.

[10] D. P. Sakalkale, P. F. Sharkey, K. Eng, W. J. Hozack, and R. H. Rothman, "Effect of femoral component offset on polyethylene wear in total hip arthroplasty," Clinical Orthopaedics and Related Research, no. 388, pp. 125-134, 2001.

[11] K. Hirakawa, N. Mitsugi, T. Koshino, T. Saito, Y. Hirasawa, and T. Kubo, "Effect of acetabular cup position and orientation in cemented total hip arthroplasty," Clinical Orthopaedics and Related Research, vol. 388, pp. 135-142, 2001.

[12] J. Charnley, "Arthroplasty of the hip. A new operation," The Lancet, vol. 277, no. 7187, pp. 1129-1132, 1961.

[13] M. N. Charles, R. B. Bourne, J. R. Davey, A. S. Greenwald, B. F. Morrey, and C. H. Rorabeck, "Soft-tissue balancing of the hip: the role of femoral offset restoration," The Journal of Bone \& Joint Surgery-American Volume, vol. 86, no. 5, pp. 1078-1088, 2004.

[14] C. S. Ranawat, L. D. Dorr, and A. E. Inglis, "Total hip arthroplasty in protrusio acetabuli of rheumatoid arthritis," Journal of Bone and Joint Surgery Series: A, vol. 62, no. 7, pp. 1059-1065, 1980.

[15] F. Pierchon, H. Migaud, A. Duquennoy, and C. Fontaine, "Radiologic evaluation of the rotation center of the hip," Revue de Chirurgie Orthopedique et Reparatrice de l'Appareil Moteur, vol. 79, no. 4, pp. 281-284, 1993.

[16] M. H. Fessy, A. N'diaye, J. P. Carret, and L. P. Fischer, "Locating the center of rotation of the hip," Surgical and Radiologic Anatomy, vol. 21, no. 4, pp. 247-250, 1999.

[17] J. F. John and P. E. Fisher, "Radiographic determination of the anatomic hip joint center: a cadaver study," Acta Orthopaedica, vol. 65 , no. 5, pp. 509-510, 1994.

[18] R. T. Loder, A. A. Mehbod, C. Meyer, and M. Meisterling, "Acetabular depth and race in young adults: a potential explanation of the differences in the prevalence of slipped capital femoral epiphysis between different racial groups?" Journal of Pediatric Orthopaedics, vol. 23, no. 6, pp. 699-702, 2003.

[19] M. L. Patriquin, M. Steyn, and S. R. Loth, "Metric analysis of sex differences in South African black and white pelves," Forensic Science International, vol. 147, no. 2-3, pp. 119-127, 2005.

[20] T. Kanemura, G. Yoshida, and Y. Ishikawa, "Sagittal spinopelvic aligment in an asymptomatic Japanese populationcomparison of western population," Journal of Spine Research, vol. 2, no. 1, pp. 52-58, 2011.

[21] C. B. D. Lavy, B. C. Msamati, and P. S. Igbigbi, "Racial and gender variations in adult hip morphology," International Orthopaedics, vol. 27, no. 6, pp. 331-333, 2003.

[22] M. D. Schofer, P. Thomas, T. J. Heyse, J. Schmitt, and U. Boudriot, "Radiological determination of the anatomic hip centre from pelvic landmarks," Acta Orthopaedica Belgica, vol. 76, no. 4, pp. 479-485, 2010.

[23] S. J. Schroder and R. Schwarzkopf, "Total hip arthroplastytemplating," in Modern Techniques in Total Hip Arthroplasty: From Primary to Complex, R. Schwarzkopf, Ed., pp. 9-20, Jaypee Medical Publishers, New Delhi, India, 2014.

[24] G. Fujii, M. Sakurai, K. Funayama, and H. Hoshi, "Radiological studies on the hip joint in adult Japanese," Seikeigeka, vol. 45, no. 8, pp. 773-780, 1994 (Japanese).

[25] T. Hisatome, J. Hori, Y. Masuda, and Y. Sasashige, "Effect of femoral offset on abductor muscle strength after total hip arthroplasty," Hip Joint, vol. 33, pp. 244-248, 2007 (Japanese).

[26] P. C. Noble, J. W. Alexander, L. J. Lindahl, D. T. Yew, W. M. Granberry, and H. S. Tullos, "The anatomic basis of femoral 
component design," Clinical Orthopaedics and Related Research, vol. 235, pp. 148-165, 1988.

[27] G. Lecerf, M. H. Fessy, R. Philippot et al., "Femoral offset: anatomical concept, definition, assessment, implications for preoperative templating and hip arthroplasty," Orthopaedics \& Traumatology: Surgery \& Research, vol. 95, no. 3, pp. 210-219, 2009.

[28] E. Sariali, A. Mouttet, G. Pasquier, and E. Durante, "Threedimensional hip anatomy in osteoarthritis. Analysis of the femoral offset," The Journal of Arthroplasty, vol. 24, no. 6, pp. 990-997, 2009.

[29] W. G. Paprosky and R. E. Magnus, "Principles of bone grafting in revision total hip arthroplasty: acetabular technique," Clinical Orthopaedics and Related Research, vol. 298, pp. 147-155, 1994.

[30] D. Garbuz, E. Morsi, and A. E. Gross, "Revision of the acetabular component of a total hip arthroplasty with a massive structural allograft: study with a minimum five-year follow-up," Journal of Bone and Joint Surgery Series: A, vol. 78, no. 5, pp. 693-697, 1996.

[31] A. B. Joshi, J. Lee, and C. Christensen, "Results for a custom acetabular component for acetabular deficiency," The Journal of Arthroplasty, vol. 17, no. 5, pp. 643-648, 2002.

[32] J. T. Dearborn and W. H. Harris, "Acetabular revision arthroplasty using so-called jumbo cementless components: an average 7-year follow-up study," The Journal of Arthroplasty, vol. 15, no. 1, pp. 8-15, 2000.

[33] A. L. Whaley, D. J. Berry, and W. Scott Harmsen, "Extra-large uncemented hemispherical acetabular components for revision total hip arthroplasty," Journal of Bone and Joint Surgery Series: A, vol. 83, no. 9, pp. 1352-1357, 2001.

[34] S. S. Kelley, "High hip center in revision arthroplasty," The Journal of Arthroplasty, vol. 9, no. 5, pp. 503-510, 1994. 


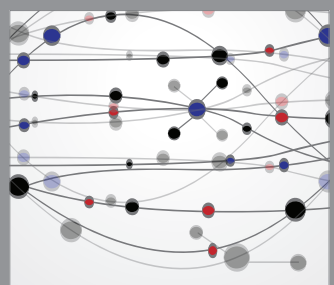

The Scientific World Journal
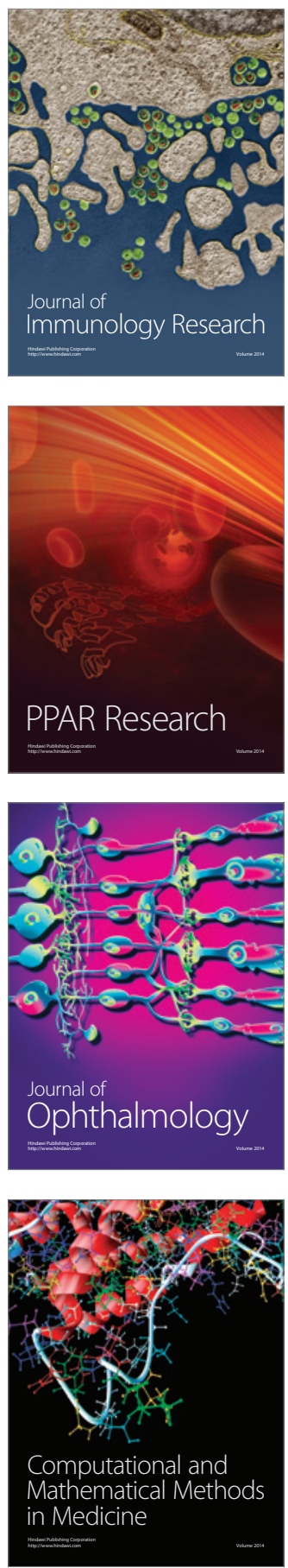

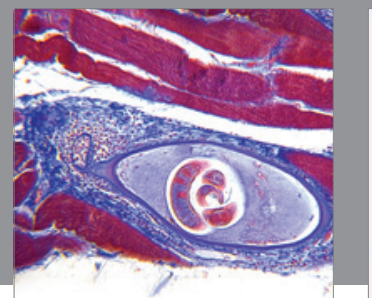

Gastroenterology

Research and Practice
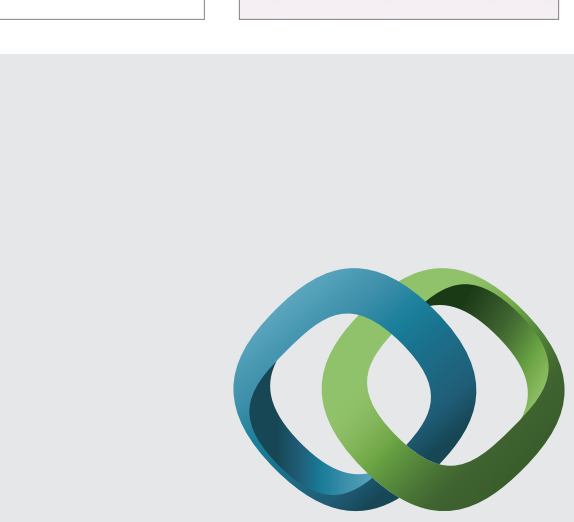

\section{Hindawi}

Submit your manuscripts at

http://www.hindawi.com
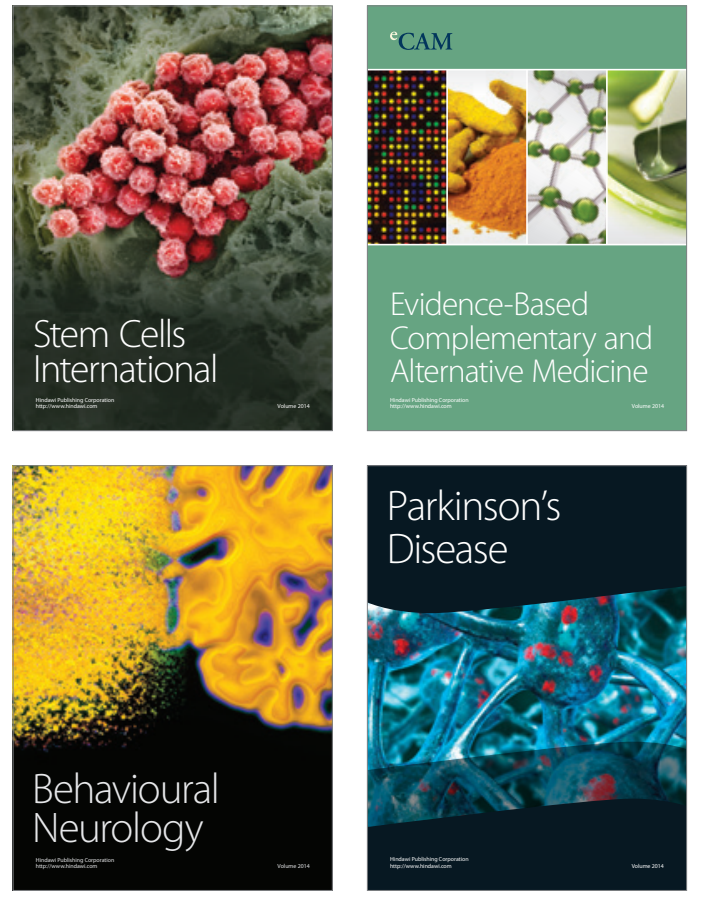
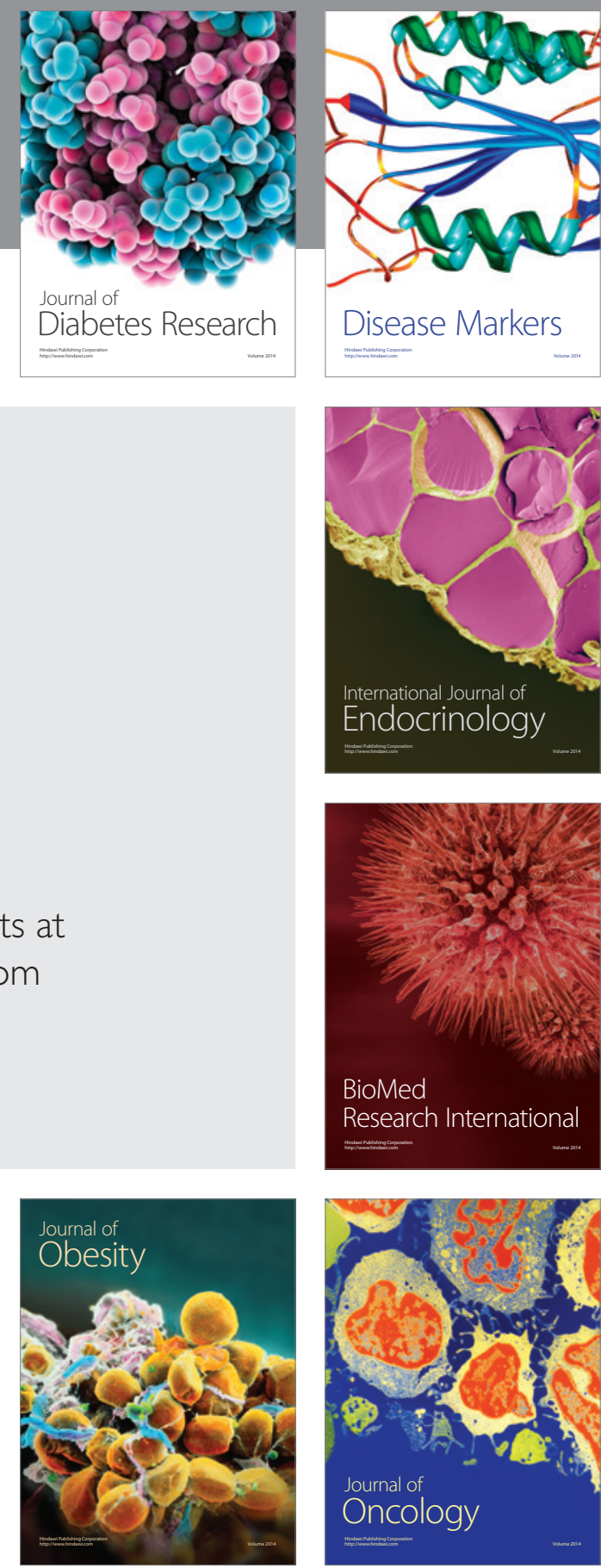

Disease Markers
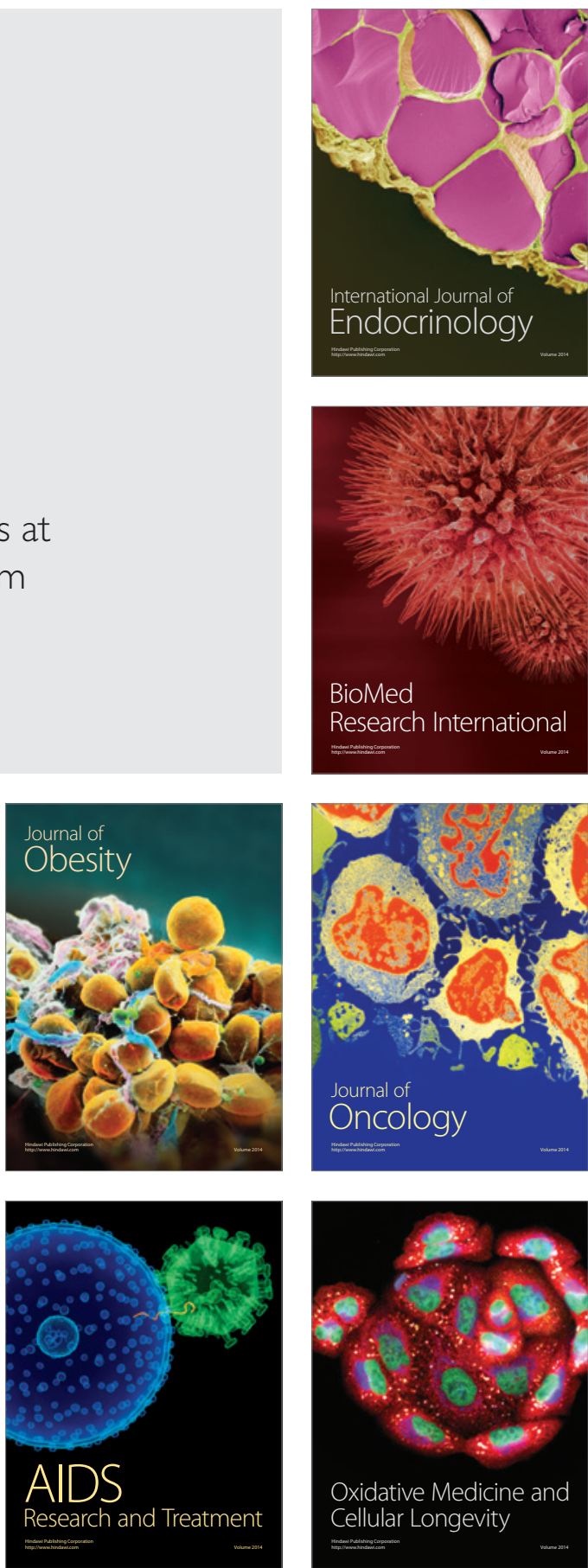